\title{
Invasion syndromes: hypotheses on relationships among invasive species attributes and characteristics of invaded sites
}

\author{
Lora B PERKINS ${ }^{1 *}$, Robert S NOWAK ${ }^{2}$ \\ ${ }^{1}$ Department of Natural Resource Management, South Dakota State University, Brookings SD 57007, USA; \\ ${ }^{2}$ Department of Natural Resources \& Environmental Science, University of Nevada, Reno NV 89557, USA
}

\begin{abstract}
As invasion science accepts that there is no single causal factor for biological invasion, the identification of groups of traits that are often associated, or "syndromes", is a logical move forward. Invasion syndromes are proposed to identify suites of site conditions (biotic and environmental) that render a site vulnerable to invasion by different types of invaders. This paper proposed four invasion syndromes which relate invader attributes (competitive ability, niche construction, phenotypic plasticity, and phenological niche separation) to the biotic characteristics (biodiversity and enemies) and environmental conditions (resource abundance and fluctuation) of invaded sites. The four invasion syndromes described in this paper are a development of hypotheses of how the many factors that influence species invasion might be associated. Invasion Syndrome 1 proposes that sites with relatively high resource abundance and high diversity should be vulnerable to invasion by species with high competitive ability. Invasion Syndrome 2 hypothesizes that sites with relatively low resource abundance and low diversity should be vulnerable to invasion by species with niche construction ability. Invasion Syndrome 3 postulates that sites with moderate or fluctuating resources and moderate diversity should be vulnerable to invasion by species with high phenotypic plasticity. Invasion Syndrome 4 hypothesizes that species introduced into a site where it has phenological niche separation from natives will not have to contend with interference from the biotic community at a site (diversity or natural enemies) and may invade where ever site environmental conditions suit its life history. Further work is needed to support, contradict, or refine these hypotheses and almost certainly will identify more invasion syndromes.
\end{abstract}

Keywords: non-native; competitive ability; niche construction; ecosystem engineering; phenotypic plasticity; phenological niche separation

Citation: Lora B PERKINS, Robert S NOWAK. 2013. Invasion syndromes: hypotheses on relationships among invasive species attributes and characteristics of invaded sites. Journal of Arid Land, 5(3): 275-283.

Non-native species are present in most ecosystems on earth, ranging from alpine zones in the Andes (MolinaMontenegro et al., 2012), to low elevation hot deserts in the United States (Holmquist et al., 2011), to retreating glacier fields in the Antarctic (Olech and Chwedorzewska, 2011), and to European hedgerows (Deckers et al., 2005). The presence of non-native species can create either positive or negative impacts
(Eviner et al., 2012; Pyšek et al., 2012). Beyond the hackneyed example of non-native crop plants, positive effects of non-native species include invasive plants increasing native pollinator abundance in novel ecosystems (Schweiger et al., 2010) and invasive shellfish increasing prey and decreasing overwinter mortality of generalist predators (Caldow et al., 2007). Myriad negative impacts of non-native species have been docu-

*Corresponding author: Lora B PERKINS (E-mail: lora.perkins@sdstate.edu)

Received 2012-11-29; revised 2013-01-29; accepted 2012-02-23

(C) Xinjiang Institute of Ecology and Geography, Chinese Academy of Sciences, Science Press and Springer-Verlag Berlin Heidelberg 2013 
mented, including altered ecosystem services such as decreased flood control, altered fire regime, and altered nutrient retention (Mack et al., 2000; Levine et al., 2003; Eviner et al., 2012).

Because of the diverse types and vast number of sites that experience non-native species invasion, a fundamental question in invasion science asks which characteristics of a site render it vulnerable to invasion. This question has generated many hypotheses regarding the potential for either site biotic characteristics or site environmental conditions to preclude invasion (Richardson and Pyšek, 2006; Catford et al., 2009; Perkins et al., 2011). Two biotic characteristics of the sites that are often examined in relation to invisibility are the richness and diversity of native species (Elton, 1958) and the amount of natural enemies (disease, herbivores, and predators) present at a site (Maron and Vilà, 2001). Site environmental conditions such as resource (e.g. light, water, nutrients, and space) abundance also impact the vulnerability of a site to invasion (Elton, 1958; Davis et al., 2000; Mack et al., 2000; Shea and Chesson, 2002). Accumulating evidence suggests that both site biotic characteristics and environmental conditions (Fig. 1) may explain a significant proportion of observed invasion on the landscape (Catford et al., 2011).

After being introduced into a new environment, some non-native species become established, successfully reproduce, and eventually experience population growth enough to create negative impact (i.e. alter ecosystem services) in the invaded site, and thus become "invasive" (Alpert et al., 2000). However, the percent of all introduced species that become invasive is small (e.g. the "Ten's Rule"; Richardson et al., 2000; but see Jeschke et al., 2012). Accordingly, another central question in invasion science is: what are the characteristics of this subset of introduced species that allow them to become invaders? Nearly 50 years of research on this question has led to the conclusion that there is no single life history trait that confers invasive ability (Baker, 1974; Alpert et al., 2000). However, groups of traits (or "invader attributes") common among select invaders have been found, such as competitive ability, phenotypic plasticity, niche construction (i.e. ecosystem engineering; Cuddington and Hastings, 2004;
Kylafis and Loreau, 2008), and phenological niche separation (Wolkovich and Cleland, 2011). Invaders may have arrived with these attributes or they may have developed after arrival through microevolutionary change (Blossey and Notzold, 1995), enemy release (Keane and Crawley, 2002), or genetic assimilation (Richards et al., 2006). Extensive published research regarding each of these hypotheses suggests that each one of these attributes (competitive ability, phenotypic plasticity, niche construction, and phenological niche separation) is a mechanism by which some, but not all, species become invasive.

Although invasion science has had limited success in determining characteristics of environments or species attributes that consistently predict invasion (Jeschke et al., 2012), abandoning the discipline (Davis et al., 2011) is not the answer. It is intuitively and empirically apparent that a trait that allows species to exist in one ecosystem might not benefit them in other ecosystems (e.g. hydrophilic plants are not widespread in upland steppe). Therefore, it is reasonable to surmise that the same attribute by which a species invades one site (i.e. a site with relatively low resources and low species richness) might not confer the same advantage at another site (i.e. a site with relatively high resources and high species richness). However, attributes that enable a species to invade a site with certain conditions may enable another species with the same attributes to invade that site or other sites with the similar conditions. For example, the attributes that enable a species to invade a site with a high resource abundance and high biodiversity in one ecosystem may enable another species with the same attributes to invade a site with high resource abundance and high biodiversity in that same or another ecosystem. Consideration of these invader-ecosystem interactions has the potential to improve understanding of invasions (Jeschke et al., 2012).

Similar to pollination syndromes that identify suites of floral traits that appeal to different types of pollinators, invasion syndromes are proposed to identify suites of site conditions (biotic and environmental) that render a site vulnerable to invasion by different types of invaders. Invasion syndromes are developed to evaluate whether invaders with similar attributes 
tend to invade areas with similar conditions. These invasion syndromes are hypotheses built on available information and theories, and require rigorous testing and likely revision. Factors such as propagule pressure, climate matching, and habitat suitability (Lockwood et al., 2005; Stohlgren et al., 2005; Von Holle and Simberloff, 2005; Catford et al., 2011; Perkins et al., 2011) are very important for invasion; however these factors are outside the scope of the invasion syndromes developed in this paper. These invasion syndromes are expected to apply after a species has passed the geographic, local environmental, and reproductive barriers of invasion (Richardson et al., 2000). In this paper, invasion syndromes are developed and described. First, to establish background, each factor (diversity, natural enemies, resource abundance, competitive ability, phenotypic plasticity, niche construction, and phenological niche separation) is briefly reviewed.

Of the several theoretical frameworks for invasion that are available (Barney and Whitlow, 2008; Catford et al., 2009; Perkins et al., 2011), the invasion triangle (Perkins et al., 2011) is most suitable for depicting invasion syndromes. The invasion triangle breaks all the factors that influence invasion into three groups: invader attributes, site biotic characteristics, and site environmental conditions (Fig. 1). Invader attributes are species traits that affect a species' invasive potential. Site biotic characteristics are intrinsic biological

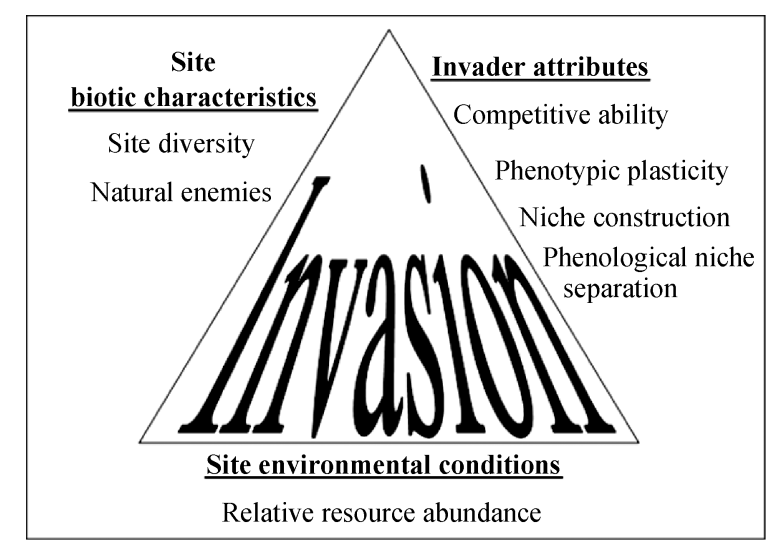

Fig. 1 Invasion triangle (adapted from Perkins et al., 2011) depicting invader attributes, site biotic characteristics, and site environmental conditions that influence biological species invasion. The invasion triangle is a conceptual framework and does not necessarily represent multivariate space. The triangle is used here to organize and concisely communicate the factors and hypotheses included in the four invasion syndromes presented in the text and in Fig. 3. characteristics of a site that influence its vulnerability to invasion. Site environmental conditions (e.g. resource abundance) are inherent environmental or physical conditions of a site that influence its invisibility (Perkins et al., 2011).

\section{Biotic characteristics and environ- mental conditions}

Many hypotheses address the role of site biotic characteristics and site environmental conditions in species invasion (see review by Perkins et al., 2011). To develop invasion syndromes, these invasion hypotheses are synthesized with the goal of addressing factors that most directly influence non-native species performance at a site: the site biotic characteristics of diversity (the richness and diversity of organisms of similar life form to the invader) and natural enemies (pathogens, predators, and herbivores), and the site environmental conditions of relative resource abundance (i.e. fertility) and resource fluctuation. We will briefly describe each and then discuss our assumptions of the relationships among these factors.

The amount, richness, or diversity of species present can affect the vulnerability of a site to invasion (diversity-invisibility hypothesis; Elton, 1958) within a given set of extrinsic factors (i.e. at given scale or among similar ecological sites; Shea and Chesson, 2002). This concept has been ardently debated and has both supportive and contradictory evidence (Levine, 2000; Mack et al., 2000; Wardle, 2001; Kennedy et al., 2002; Stohlgren et al., 2003). Sites with higher diversity can be (Kennedy et al., 2002), but are not always (Stohlgren et al., 2003), resistant to invasion. Diversity can impact the vulnerability of a site to invasion in a number of ways including: 1) as diversity increases, so does the probability of a species being present that has the ability to successfully compete with or otherwise resist an invader; and 2) as diversity increases, resources are more completely utilized making the site more resistant to invasion (Wardle, 2001).

Natural enemies, such as generalist pathogens, herbivores, granivores, and predators, present at a site can provide some resistance to invasion (Levine et al., 
2004). Sites with natural enemies that create large impacts on invaders should be more resistant to invasion and less invisible than sites with small natural enemy impacts (Levine et al., 2004). Natural enemies have been observed to limit the performance and spread of (D'Antonio, 1993; Cushman et al., 2011), but not necessarily eliminate non-native species (Levine et al., 2004).

The amount of resources available at a site influence how species, both native and non-native, perform. Resource distribution is not homogenous: some sites will be more resource rich and fertile (and therefore less stressful) than other sites within a given set of extrinsic factors (i.e. at given scale or among similar ecological sites; Shea and Chesson, 2002). This resource distribution will affect the vulnerability of the site to invasion. Often, local habitat properties (Chytry et al., 2008), resource abundance (Larson et al., 2001), and physical stress (He et al., 2012) are the most influential factors in determining invisibility. Resource abundance and environmental stress can affect both the performance and the identity (MacDougall et al., 2006) of invaders.

Beyond the dichotomy of resource rich and resource poor sites, fluctuation of resources also influence the invisibility of a site (Davis et al., 2000). Every site has some natural level of fluctuation (increase or decrease) of resource abundance throughout the year (i.e. decrease in soil nutrients throughout the growing season due to plant uptake); however, some sites have very extreme and pronounced fluctuations of resources (i.e. soil-water in flood-prone areas; Davis et al., 2000). Resource fluctuation can also be caused by disturbance that increases the amount of unused resources either by the addition of new resources (i.e. nitrogen deposition) or through reduced uptake by the resident community. Resource fluctuations often (Davis et al., 2000), but not always (Walker et al., 2005), increase the vulnerability of a site to invasion.

\subsection{Relationship between site biotic characteristics and site environmental conditions}

Consideration of the relationship among site biotic characteristics and site environmental conditions is an initial step for the development of invasion syndromes. In order to evaluate this relationship, invasion syndromes will lean on the Exploitation Ecosystem Hypothesis (EEH) (van de Koppel et al., 1996; Oksanen and Oksanen, 2000; Rees et al., 2001). The EEH explores multitrophic relationships along a productivity or resource abundance gradient. The EEH postulates that at very low resource abundance, production is too low to support a sufficient enemy population to affect production (Rees et al., 2001; section A in Fig.2). The EEH goes on to postulate that at high resource abundance, enemy populations are either moderated by their own predators (Oksanen and Oksanen, 2000) or are too inefficient (van de Koppel et al., 1996) to substantially affect producers (section B in Fig. 2). Finally, the EEH postulates that at intermediate or fluctuating levels of resource abundance, production is adequate to support an amount of enemies that is large enough to decrease production, but not large enough to support their own predators (section C in Fig. 2; Rees et al., 2001). For example, plant production in infertile sites is too low to maintain many herbivores, thus little or no effect of herbivores on plant production exists; plant production in fertile sites is sufficient to support a large enough herbivore population that a population of the herbivore's predators can also be

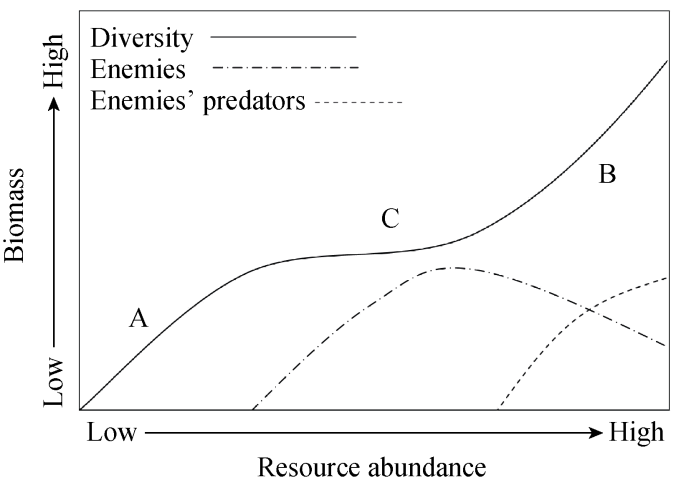

Fig. 2 Diagram showing the relationship between resource abundance, diversity, and enemies (adapted from the Exploitation Ecosystem Hypothesis; Oksanen and Oksanen, 2000). Letters indicate three postulates of the exploitation ecosystem hypothesis upon which we base four different invasion syndromes: Section A sites with low resource abundance have a low level of diversity and a low amount of enemies available to resist invasion; Section B sites with high resource abundance have a high amount diversity but a low amount of enemies available to resist invasion; and Section $\mathrm{C}$ sites with moderate or fluctuating resources have a moderate amount diversity and a high level of enemies available to resist invasion. 
sustained, thus the impact of herbivores on plant production is moderated by their own predators; finally, plant production in moderate or fluctuating resource areas is sufficient to maintain a only modest herbivore population, but this herbivore population is too small to support their own predators (herbivores are not controlled by their own predators), and thus, are able to substantially impact plant production. Invasion syndromes incorporate EEH and assume that: 1) sites with low resource abundance will have low resistance to invasion due to either "diversity" or "enemies" (section A in Fig. 2); 2) sites with high resource abundance will have high resistance to invasion due to "diversity" and low resistance to invasion due to "enemies" (section B in Fig. 2); and 3) sites with moderate resource abundance or fluctuating resources will have moderate resistance to invasion due to "diversity" and high resistance to invasion due to "enemies" (section C in Fig. 2).

It is worthy to note these invasion syndromes are using the term "biotic resistance" in a broader sense than the diversity-invisibility hypothesis paradigm. Often the diversity-invisibility hypothesis refers to the diversity of species of similar life-form to the potential invader (i.e. native plant diversity versus an invasive plant). Here, however, biotic resistance is expanded to include multi-trophic interactions as explained by the exploitation ecosystem hypothesis (van de Koppel et al., 1996; Oksanen and Oksanen 2000; Rees et al., 2001). These invasion syndromes are aimed at teasing out invader-ecosystem patterns where the entire biotic community of a site may provide resistance to invasion.

\section{Invader attributes and invasion syn- dromes}

Invader attributes are the intrinsic characteristics of a species that affect its ability to become invasive (Perkins et al., 2011). As mentioned above, attributes that currently have promise for explaining a species invasive potential are competitive ability, niche construction, phenotypic plasticity, and phenological niche separation. Each of these attributes confers invasive success in some environments but not others. Each attribute is briefly discussed and invasion syndromes hypothesized for each attribute.

\subsection{Competitive ability}

The competitive ability hypothesis is a long-standing hypothesis regarding invasive potential of species (Elton, 1958; Baker, 1974) which states that invaders are stronger competitors for limiting resources, i.e. have a stronger competitive effect (Goldberg and Landa, 1991) or larger competitive interference ability (Hart and Marshall, 2012), than natives in the invaded site. Clear evidence exists in support of and in contradiction to (Vilà and Weiner, 2004) this hypothesis. This evidence does not signify a shortcoming in the competitive ability hypothesis; this evidence suggests that the hypothesis may only apply under certain conditions or in sites with particular characteristics.

Competitive ability may not be a trait that confers advantage in all environments. The stress-gradient hypothesis (Bertness and Callaway, 1994; Maestre et al., 2009) states that competition should be a dominating force when resources are abundant compared to sites where resources are less abundant (i.e. more stressful environments). Extending the stress-gradient hypothesis to invasion, competitive ability may be an attribute that confers invasive potential in sites with higher resource abundance. Conversely, even very strong competitive ability for a resource will not overcome essential resource limitation and may not provide benefit in an environment with low resource abundance. Thus, species with high competitive ability should have a large invasive potential in areas where there are resources to compete for: sites with relatively high resource abundance. Additionally, sites with high resource abundance have more diversity than resource poor sites (see the discussion of EEH above). For competitive ability to provide benefit to an invader, population density in the recipient site must be great enough that interaction between individuals is likely to occur. In very resource poor sites, population density may be low enough that interactions between individuals are not a major factor influencing community dynamics; therefore, strong competitive ability will not provide benefit to a potential invader. 
Combining the competitive ability hypothesis and the relationships in site environmental and biotic characteristics (described above) result in Invasion Syndrome 1.
Invasion Syndrome 1: Sites with relatively high resources should have higher diversity and low enemy impact and should be vulnerable to invasion by species with high competitive ability (Fig. 3a).

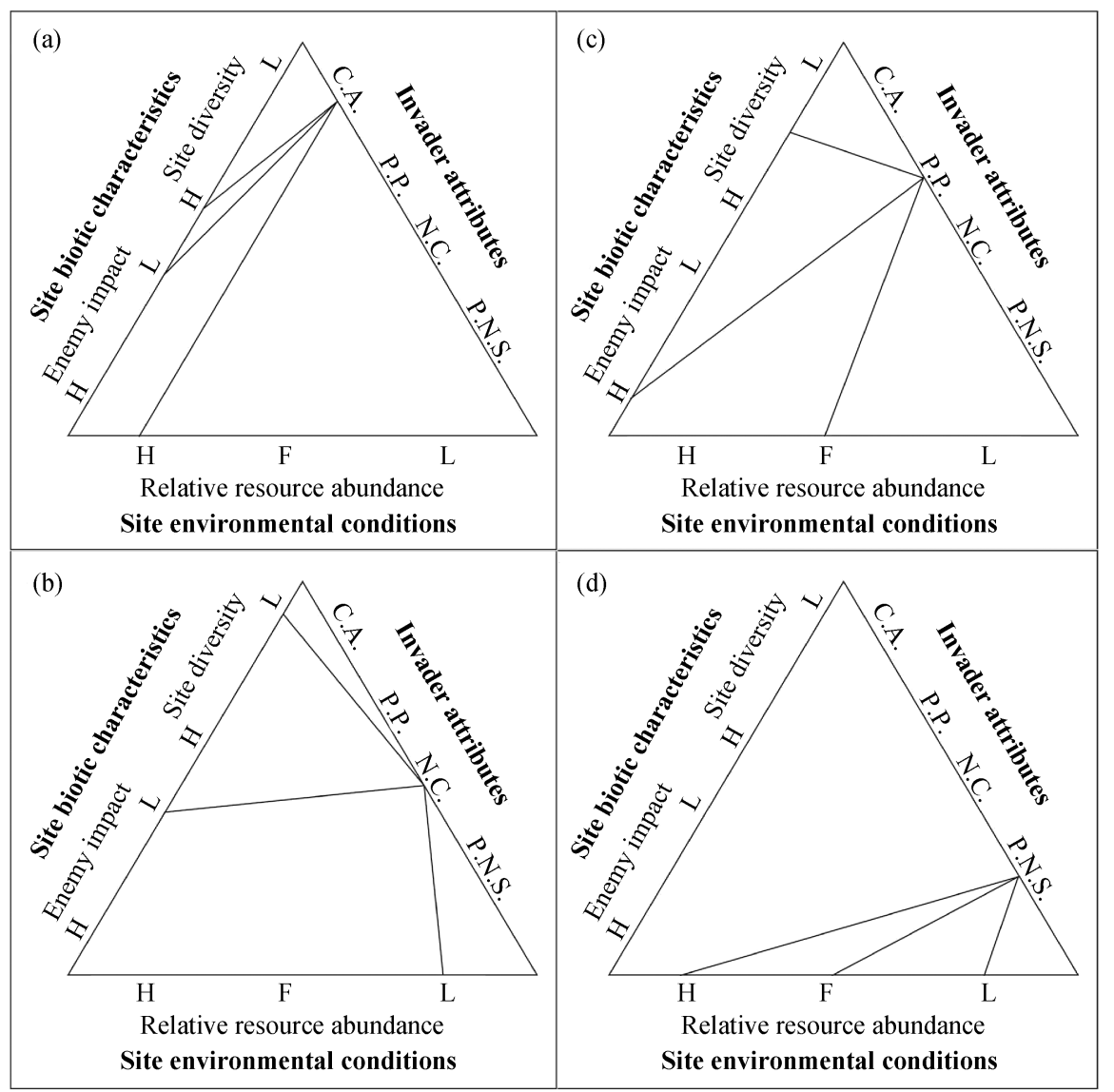

Fig. 3 Hypotheses of invasion syndromes that relate invader attributes: competitive ability (C.A.), phenotypic plasticity (P.P.), niche construction (N.C.), and phenological niche separation (P.N.S.) with site biotic characteristics of enemy impacts (i.e. disease, predators, or herbivores), and site diversity (the richness and diversity of organisms of similar life form to the invader), and relative resource abundance $(\mathrm{H}=$ high, $\mathrm{L}=\mathrm{low}$, and $\mathrm{F}=$ moderate or fluctuating). Panel a illustrates Invasion Syndrome 1 where sites with high resource abundance will have high site diversity and low enemy impacts and are vulnerable to invasion by a species with strong competitive ability. Panel $\mathrm{b}$ illustrates Invasion Syndrome 2 where sites with low resource abundance will have low diversity and low enemy impacts and should be vulnerable to invasion by species with niche construction ability. Panel c illustrates Invasion Syndrome 3 where sites with moderate or fluctuating resource abundance will have moderate site diversity and high enemy impact and should be vulnerable to invasion by species with high phenotypic plasticity. Panel d illustrates Invasion Syndrome 4 where a species with phenological niche separation from natives may avoid all resistance to invasion from site biotic characteristics and may be able to invade any site with environmental conditions that suit its life history.

\subsection{Niche construction}

The niche construction or ecosystem engineering hypothesis of invasion is based on the ability of species to alter their environment, e.g. through alteration of nutrient dynamics (Perkins and Nowak, 2013) or abundant litter production (Farrer and Goldberg, 2009), in a manner that enhances its growth and persistence (Kylafis and Loreau, 2011) and alters population dynamics (Cuddington et al., 2009). This hy- pothesis asserts that a species with the ability to modify their environment in a manner that preferentially benefits conspecifics should have more invasive potential than species without that ability (Jones et al., 1994; Cuddington and Hastings, 2004; Kylafis and Loreau, 2008, 2011; Perkins and Nowak, 2013). Species that have niche construction ability may have faster growth rates in sub-optimal habitats (low resource abundance) than other species (Cuddington and 
Hastings, 2004). Further, niche construction ability only provides substantial benefits in low-resource conditions, and the advantage of niche construction ability is lost if resource abundance is high (Kylafis and Loreau, 2008). In other words, if the environment is not stressful, there is no benefit to being able to alleviate environmental stress. Thus, niche construction may be an attribute that only increases a species invasive potential in sites with low resource abundance (i.e. high environmental stress).

Combining niche construction and the relationships in site environmental and biotic characteristics (described above) result in Invasion Syndrome 2.

Invasion Syndrome 2: Sites with relatively low resource abundance should have lower diversity and low enemy impact and should be vulnerable to invasion by species with niche construction ability (Fig. 3b).

\subsection{Phenotypic plasticity}

The phenotypic plasticity hypothesis states that invaders have a higher degree of plasticity than native species in invaded sites and those invaders have a larger plastic response of fitness traits in response to variable resources than native species in the invaded environment (Richards et al., 2006). The strong evidence in support of (e.g. the "Jack and Master" phenotypic plastic ability of invader Parkinsonia aculeata in Australia; Pichancourt and van Klinken, 2012) and in contradiction to the hypothesis (Davidson et al., 2011; Palacio-Lopez and Gianoli, 2011; Drenovsky et al., 2012) indicate that the benefit of phenotypic plasticity may be environment-dependent. However, by definition non-native species with high phenotypic plasticity should have high invasive potential in areas with fluctuating or variable resources.

Combining phenotypic plasticity and the relationships in site environmental and biotic characteristics (described above) result in Invasion Syndrome 3.

Invasion Syndrome 3: Sites with moderate or fluctuating resources should have moderate diversity and high enemy impact and should be vulnerable to invasion by species with high phenotypic plasticity (Fig. 3c).

\subsection{Phenological niche separation}

The phenological niche separation hypothesis states that a non-native species invasive potential increases when its phenology is temporally distinct from native phenology (Wolkovich and Cleland, 2011). Several dynamics exist for invader phenology to be separated from native phenology, including: vacant niche (wherein the invader grows at times during the year when natives are not active); priority effects (wherein the invader begins growth earlier than natives); or it is invaders may have a longer niche breadth (i.e. length of growing season or fruiting period) compared to natives (Wolkovich and Cleland, 2011). The foundation for this hypothesis is very similar to Elton's vacant niche hypothesis of invasion, wherein an invader is thought to be successful when it utilizes resources that are not utilized by the resident native community (Elton, 1958). A species introduced into a site where it has a phenological niche separation from the resident community may avoid any resistance to invasion due to the resident species on the site; i.e. the resident species are not active, and thus provide little competition or enemy impacts. Therefore, a non-native species with phenological niche separation from the natives present on a site may be able to invade any site with environmental conditions that suit its life history.

Invasion Syndrome 4: Species introduced into a site where it has a phenological niche separation from natives will not have to contend with interference from the biotic community at a site (diversity or natural enemies) and may invade where ever site environmental conditions suit its life history (Fig. 3d).

\section{Conclusion}

As invasion science accepts that there is no single causal factor for invasion, identification of groups of traits that are often associated or "syndromes" is a logical step. In this paper, four invasion syndromes have been hypothesized as a beginning to investigate invader-ecosystem relationships and refine understanding of biological invasion. By moving past examination of single invasion hypotheses tested with single invaders in single systems and considering at larger patterns, progress can be made. A trait that benefits a species in one environment may not be beneficial in another environment (e.g. halophiles do 
not dominate non-saline environments); therefore, it may not be reasonable to expect that all invaders succeed by the same invasive trait. Perhaps competitive ability may be a trait that confers invasive potential in sites with high resource abundance and high diversity (Invasion Syndrome 1); or niche construction (i.e. ecosystem engineering) may be a trait that increases a species invasive potential in sites with low resource abundance and low biotic resistance (Invasion Syndrome 2); or phenotypic plasticity might confer invasive potential in sites with fluctuating resources (Invasion Syndrome 3); or no specific invasive trait is needed if a potential invader has phenological niche separation from the natives present at a site (Invasion Syndrome 4). Further work is needed to support or contradict these hypotheses and almost certainly will identify more invasion syndromes.

\section{Acknowledgments}

This work was supported by the US National Science Foundation (1047575), and in part by the Nevada Agricultural Experiment Station, the South Dakota Agricultural Experiment Station, the Nevada Arid Rangeland Initiative. Thanks to the organizers and supporters of the International Symposium on Invasive Plants and Global Change in Urumqi, China in 2012 for their commendable work in building a successful meeting.

\section{References}

Alpert P, Bone E, Holzapfel C. 2000. Invasiveness, invasibility and the role of environmental stress in the spread of non-native plants. Perspectives in Plant Ecology Evolution and Systematics, 3: 52-66.

Baker H. 1974. The evolution of weeds. Annual Review of Ecology and Systematics, 5: 1-24.

Barney J N, Whitlow T H. 2008. A unifying framework for biological invasions: the state factor model. Biological Invasions, 10: 259-272.

Bertness M D, Callaway R. 1994. Positive interactions in communities. Trends in Ecology \& Evolution, 9: 191-193.

Blossey B, Notzold R. 1995. Evolution of increased competitive ability in invasive nonindigenous plants: a hypothesis. Journal of Ecology, 83: 887-889.

Caldow R W G, Stillman R A, Durell S A D, et al. 2007. Benefits to shorebirds from invasion of a non-native shellfish. Proceedings of the Royal Society B: Biological Sciences, 274: 1449-1455.

Catford J A, Jansson R, Nilsson C. 2009. Reducing redundancy in invasion ecology by integrating hypotheses into a single theoretical framework. Diversity and Distributions, 15: 22-40.

Catford J A, Vesk P A, White M D, et al. 2011. Hotspots of plant invasion predicted by propagule pressure and ecosystem characteristics.
Diversity and Distributions, 17: 1099-1110.

Chytry M, Jarosik V, Pyšek P, et al. 2008. Separating habitat invasibility by alien plants from the actual level of invasion. Ecology, 89: 1541-1553.

Cuddington K, Hastings A. 2004. Invasive engineers. Ecological Modeling, 178: 335-347.

Cuddington K, Wilson W G, Hastings A. 2009. Ecosystem engineers: feedback and population dynamics. The American Naturalist, 173: 488-498.

Cushman J H, Lortie C J, Christian C E. 2011. Native herbivores and plant facilitation mediate the performance and distribution of an invasive exotic grass. Journal of Ecology, 99: 524-531.

D'Antonio C M. 1993. Mechanisms controlling invasion of coastal plant communities by the alien succulent Carpobrotus edulis. Ecology, 74: 83-95.

Davidson A M, Jennions M, Nicotra A B. 2011. Do invasive species show higher phenotypic plasticity than native species and, if so, is it adaptive? A meta-analysis. Ecology Letters, 14: 419-431.

Davis M, Chew M K, Hobbs R J, et al. 2011. Don't judge species on their origins. Nature, 474: 153-154.

Davis M A, Grime J P, Thompson K. 2000. Fluctuating resources in plant communities: a general theory of invasibility. Journal of Ecology, 88: 528-534.

Deckers B, Verheyen K, Hermy M. 2005. Effects of landscape structure on the invasive spread of black cherry Prunus serotina in an agricultural landscape in Flanders, Belgium. Ecography, 28: 99-109.

Drenovsky R E, Khasanova A, James J J. 2012. Trait convergence and plasticity among native and invasive species in resource-poor environments. American Journal of Botany, 99: 629-639.

Elton C. 1958. The Ecology of Invasions by Animals and Plants. Chicago: University of Chicago Press.

Eviner V T, Garbach K, Baty J H. 2012. Measuring the effects of invasive plants on ecosystem services: challenges and prospects. Invasive Plant Science and Management, 5: 125-136.

Farrer E C, Goldberg D E. 2009. Litter drives ecosystem and plant community changes in cattail invasion. Ecological Applications, 19: 398-412.

Goldberg D E, Landa K. 1991. Competitive effect and response: hierarchies and correlated traits in the early stages of competition. Journal of Ecology, 79: 1013-1030.

Hart S P, Marshall D J. 2012. Advantages and disadvantages of interference-competitive ability and resource-use efficiency when invading established communities. Oikos, 121: 396-402.

He Q, Cui B S, An Y. 2012. Physical stress, not biotic interactions, preclude an invasive grass from establishing in forb-dominated salt marshes. PLos One, 7: e33164.

Holmquist J G, Schmidt-Gengenbach J, Slaton M R. 2011. Influence of invasive palms on terrestrial arthropod assemblages in desert spring habitat. Biological Conservation, 144: 518-525.

Jeschke J M, Gómez Aparicio L, Haider S, et al. 2012. Support for major hypotheses in invasion biology is uneven and declining. NeoBiota, 14: $1-20$.

Jones C G, Lawton J H, Shachak M. 1994. Organisms as ecosystem engineers. Oikos, 69: 373-386. 
Keane R M, Crawley M J. 2002. Exotic plant invasions and the enemy release hypothesis. Trends in Ecology \& Evolution, 17: 164-170.

Kennedy T A, Naeem S, Howe K M, et al. 2002. Biodiversity as a barrier to ecological invasion. Nature, 417: 636-638.

Kylafis G, Loreau M. 2008. Ecological and evolutionary consequences of niche construction for its agent. Ecology Letters, 11: 1072-1081.

Kylafis G, Loreau M. 2011. Niche construction in the light of niche theory. Ecology Letters, 14: 82-90.

Larson D L, Anderson P J, Newton W. 2001. Alien plant invasion in mixed-grass prairie: effects of vegetation type and anthropogenic disturbance. Ecological Applications, 11: 128-141.

Levine J M. 2000. Species diversity and biological invasions: relating local process to community pattern. Science, 288: 852-854.

Levine J M, Vilà M, Antonio C M D. 2003. Mechanisms underlying the impacts of exotic plant invasions. Proceedings of the Royal Society of London Series B: Biological Sciences, 270: 775-781.

Levine J M, Adler P B, Yelenik S G. 2004. A meta-analysis of biotic resistance to exotic plant invasions. Ecology Letters, 7: 975-989.

Lockwood J L, Cassey P, Blackburn T. 2005. The role of propagule pressure in explaining species invasions. Trends in Ecology \& Evolution, 20: 223-228.

MacDougall A S, Boucher J, Turkington R. 2006. Patterns of plant invasion along an environmental stress gradient. Journal of Vegetation Science, 17: 47-56.

Mack R N, Simberloff D, Lonsdale W M, et al. 2000. Biotic invasions: causes, epidemiology, global consequences, and control. Ecological Applications, 10: 689-710.

Maestre F T, Callaway R M, Valladares F, et al. 2009. Refining the stress-gradient hypothesis for competition and facilitation in plant communities. Journal of Ecology, 97: 199-205.

Maron J L, Vilà M. 2001. When do herbivores affect plant invasion? Evidence for the natural enemies and biotic resistance hypotheses. Oikos, 95: 361-373.

Molina-Montenegro M A, Penuelas J, Munne-Bosch S, et al. 2012. Higher plasticity in ecophysiological traits enhances the performance and invasion success of Taraxacum officinale (dandelion) in alpine environments. Biological Invasions, 14: 21-33.

Oksanen L, Oksanen T. 2000. The logic and realism of the hypothesis of exploitation ecosystems. American Naturalist, 155: 703-723.

Olech M, Chwedorzewska K J. 2011. The first appearance and establishment of an alien vascular plant in natural habitats on the forefield of a retreating glacier in Antarctica. Antarctic Science, 23: 153-154.

Palacio-Lopez K, Gianoli E. 2011. Invasive plants do not display greater phenotypic plasticity than their native or non-invasive counterparts: a meta-analysis. Oikos, 120: 1393-1401.

Perkins L B, Leger E A, Nowak R S. 2011. Invasion triangle: an organizational framework for species invasion. Ecology and Evolution, 1: 610-625.

Perkins L B, Nowak R S. 2013. Native and non-native grasses generate common types of plant-soil feedbacks by altering soil nutrients and microbial communities. Oikos, 122: 199-208.

Pichancourt J B, van Klinken R D. 2012. Phenotypic plasticity influences the size, shape and dynamics of the geographic distribution of an invasive plant. PLos One, 7: 12.

Pyšek P, Jarosik V, Hulme P E, et al. 2012. A global assessment of invasive plant impacts on resident species, communities and ecosystems: the interaction of impact measures, invading species' traits and environment. Global Change Biology, 18: 1725-1737.

Rees M, Condit R, Crawley M, et al. 2001. Long-term studies of vegetation dynamics. Science, 293: 650-655.

Richards C L, Bossdorf O, Muth N Z, et al. 2006. Jack of all trades, master of some? On the role of phenotypic plasticity in plant invasions. Ecology Letters, 9: 981-993.

Richardson D M, Pyšek P, Rejmanek M, et al. 2000. Naturalization and invasion of alien plants: concepts and definitions. Diversity and Distributions, 6: 93-107.

Richardson D M, Pyšek P. 2006. Plant invasions: merging the concepts of species invasiveness and community invasibility. Progress in Physical Geography, 30: 409-431.

Schweiger O, Biesmeijer J C, Bommarco R, et al. 2010. Multiple stressors on biotic interactions: how climate change and alien species interact to affect pollination. Biological Reviews, 85: 777-795.

Shea K, Chesson P. 2002. Community ecology theory as a framework for biological invasions. Trends in Ecology \& Evolution, 17: $170-176$.

Stohlgren T J, Barnett D T, Kartesz J. 2003. The rich get richer: patterns of plant invasions in the United States. Frontiers in Ecology and the Environment, 1: 11-14.

Stohlgren T J, Crosier C, Chong G W, et al. 2005. Life-history habitat matching in invading non-native plant species. Plant and Soil, 277: $7-18$.

van de Koppel J, Huisman J, van der Wal R, et al. 1996. Patterns of herbivory along a productivity gradient: an empirical and theoretical investigation. Ecology, 77: 736-745.

Vilà M, Weiner J. 2004. Are invasive plant species better competitors than native plant species? Evidence from pair-wise experiments. Oikos, 105: 229-238.

Von Holle B, Simberloff D. 2005. Ecological resistance to biological invasion overwhelmed by propagule pressure. Ecology, 86: 3212-3218.

Walker S, Wilson J B, Lee W G. 2005. Does fluctuating resource availability increase invasibility? Evidence from field experiments in New Zealand short tussock grassland. Biological Invasions, 7: 195-211.

Wardle D A. 2001. Experimental demonstration that plant diversity reduces invasibility-evidence of a biological mechanism or a consequence of sampling effect? Oikos, 95: 161-170.

Wolkovich E M, Cleland E E. 2011. The phenology of plant invasions: a community ecology perspective. Frontiers in Ecology and the Environment, 9: 287-294. 